\title{
(t)
}

\section{A FAMÍLIA MONOGÂMICA, O AMOR INDIVIDUAL SEXUADO E A EMANCIPAÇÃO DA MULHER}

\author{
MONOGAMOUS FAMILY, SEXED INDIVIDUAL \\ LOVE AND EMANCIPATION OF WOMAN
}

\section{Rogério Castro}

Submetido em 12/04/2014

Aceito em 11/07/2014

Abaixo a família monogâmica!

Autor: Sérgio Lessa

São Paulo: Editora Instituto Lukács, 2012.

Um livro importante, necessário e esclarecedor encontra-se disponível para o público brasileiro desde o final de 2012 - Abaixo a família monogâmica! -, do filósofo e professor da Universidade Federal de Alagoas (UFAL) Sérgio Lessa. O objeto de sua minuciosa e cuidadosa investigação é a origem e o desenvolvimento da organização familiar monogâmica, fundada, segundo a leitura do autor, com o advento da sociedade de classes e a propriedade privada.

Partindo do fato de que nas sociedades primitivas, aquelas que não conheceram a propriedade privada, as tarefas domésticas, como a criação dos filhos, eram função de todos da comunidade, e não apenas de uma família particular, Lessa explica, numa exposição equilibrada e nada mecanicista, que, somente após a Revolução Neolítica e o surgimento da sociedade escravista, o complexo social total vai exigir um outro tipo de organização

1 Doutorando em Serviço Social pela Universidade Federal do Rio de Janeiro. Mestre em Serviço Social pela Universidade Federal de Alagoas (UFAL). Professor da Universidade Paulista - UNIP. E-mail: rogeriocastrouesb@hotmail.com 


\section{temporalis}

familiar, na qual tais tarefas passam a ter um caráter privado, em virtude de o senhor de escravos, agora, não mais poder assumir como suas funções que não estejam de acordo com a propriedade privada (individualismo intrínseco à propriedade). Esse descolamento da família do coletivo e a sua constituição enquanto núcleo privado dão origem, portanto, à família monogâmica ou nuclear.

As implicações desse acontecimento para a criação das crianças, o consequente direcionamento da mulher para tais atividades e o posterior confinamento e limitação de seu horizonte são analisados com tal maestria que o leitor somente terá ideia quando se deparar com a explicação de que da referida condição é que se elucidam o papel secundário da mulher, a sua ausência da vida social e pública (reduzida agora aos papéis de esposas e prostitutas), a sua quase inexistente inserção nas artes por longo período da História, a sua condição de subalterna no interior de uma estrutura patriarcal, o que explica o baixo desenvolvimento das individuações das pessoas do sexo feminino.

A família monogâmica tem no homem o provedor e dele a mulher deve aceitar a superioridade e respeitar, mas somente na sua presença, pois, quando ausente, ela assume o papel de cuidar das crianças com a violência e a ameaça peculiares à sociedade de classes e de dar ordens aos serviçais. Além disso, para as crianças, o seu isolamento agora do convívio com as outras traz fortes implicações ao seu desenvolvimento, como, por exemplo, a introjeção, se pertencerem às classes abastadas, desde cedo, do ser classe dominante em suas personalidades, graças ao convívio com serviçais no espaço doméstico.

O autor argumenta que, do consenso do período anterior, o ato sexual se revestiu pela dominação na relação entre homens e mulheres, que passam a se relacionar entre maridos e esposas e senhores e prostitutas, conforme defende o autor. Segundo ele: "No primeiro caso, a finalidade é um herdeiro que possa perpetuar a acumulação de riqueza da família. Esta, por sua vez, tem seu status na sociedade a partir da propriedade que possui" ( $p$. 31). A garantia de que o filho é do marido deve-se à virgindade da esposa, e ser atraente para o sexo oposto é ser uma exímia 
cozinheira e uma boa zeladora do lar - ou seja, suportar com resignação a repressão ao desenvolvimento da sua personalidade, inclusive da sua sexualidade. O prazer no ato sexual é algo exclusivo do sexo masculino, negado às mulheres: "a esposa tem a obrigação de 'sofrer' para procriar". "As mulheres podem viver sem sexo, os homens jamais", escreve Lessa. A figura da prostituta, por outro lado, prova que a monogamia, no sentido antropológico de uma relação exclusivista, é algo que vale para as esposas, mas não para os homens.

É somente com Romeu e Julieta que a necessidade afetiva dos indivíduos torna-se reconhecida pela primeira vez na História. Melhor morrer do que não realizar o amor passa a ser o lema que embala Romeu e Julieta na luta contra as relações familiares, a tradição e os costumes. É a entrada na História do amor individual sexuado, do qual fala Engels, um amor que supõe a reciprocidade no ser amado, bem como atinge um grau de intensidade e de duração que transforma em grande desventura, para os amantes, a separação ou a falta de relações íntimas. Ademais, um novo critério moral surge para julgar as relações sexuais - "são filhas do amor e de um afeto recíproco?" (ENGELS, 2010, p. 101). De acordo com Lessa:

Os humanos descobrem que a relação afetiva pode ter uma dimensão, uma riqueza, uma intensidade, um prazer, uma densidade, uma capacidade de abarcar toda a existência que a faz, de modo inédito na história, um dos elementos imprescindíveis da vida individual (p. 52-53, grifo nosso).

Uma existência carente de amor, agora, é quase como uma existência não digna de ser vivida. Mas o cenário da tragédia estava anunciado. Numa sociedade em que o interesse privado, a cobiça, o egoísmo, o status - todos eles emanando da propriedade privada - emolduram o terreno no interior do qual se situam os indivíduos, o espaço para o verdadeiro amor estaria obstaculizado, quando não interditado. A esse respeito, escreve Engels (2010, p. 103): “[...] o matrimônio começou a depender inteiramente de considerações econômicas". E continua o autor alemão: "Na prática, e desde o princípio, se havia alguma coisa inconcebível para as classes dominantes era que a inclinação 


\section{temporalis}

mútua dos interessados pudesse ser a razão por excelência do matrimônio. Isso só se passava nos romances ou entre as classes oprimidas - que não contavam para nada" (ibidem apud p. 55).

O desenvolvimento das forças produtivas trazia em seu bojo novas condições para a família monogâmica burguesa. O marido, provedor e dominante, agora tem cada vez mais dificuldades em manter o lar em ordem, já que o crescimento das cidades facilitaria a "infidelidade" da esposa, a sexualidade estaria entrando com mais força na vida cotidiana e, com a Revolução Industrial, a mão de obra feminina ia se tornando imensa fonte de extração de mais-valia. Escreve o autor de Abaixo a família monogâmica!:

A violência continua a ser fundamental para manter a família monogâmica nos eixos... agora, burgueses. A Constituição napoleônica de 1806, a primeira modernamente burguesa, pune com a morte a infidelidade feminina e legaliza a poligamia masculina estabelecendo o direito de o homem ter tantas amantes quanto queira, desde que a cada uma dê uma casa separada (p. 56-57).

O trânsito da era da carência para a da abundância constitui o "cenário trágico do amor". É nele que o casamento burguês atinge a sua maturidade, na Europa vitoriana. Nesse contexto, o amor sexuado individual adquire novos impulsos, necessidades qualitativamente novas, de modo que as pessoas que são maridos e esposas vão caber cada vez menos em seus papéis sociais - "a prostituição para os homens e os amantes para as mulheres convertem-se em mediações pelas quais tais necessidades vão também se expressar em escala social crescente" ( $p$. 70). Aumenta, portanto, na era vitoriana, o antagonismo entre a família monogâmica burguesa e as necessidades afetivas dos indivíduos, intensificando, por exemplo, a repressão e a conhecida hipocrisia burguesa. As transgressões seriam rigidamente punidas. Há, então, a intensificação do antagonismo entre as necessidades afetivas dos indivíduos e o casamento monogâmico no século XIX. A dissociação crescente entre amor e sexualidade da família monogâmica burguesa vai sendo atestada pela forma como as relações afetivas vão se conformando: submetidas a tensões e contradições maiores que no passado, as mulheres 
conhecem uma nova doença, a histeria, e os homens vão se brutalizando, sendo o sexo uma necessidade socialmente reconhecida do "macho", já os afetos, "coisas de mulher".

Uma vez que a abundância possibilita e requer, necessariamente, o desenvolvimento afetivo e racional das pessoas, aumentam as dificuldades para impor a fidelidade feminina numa sociedade que está se urbanizando e na qual os contatos sociais vão se tornando cada vez mais frequentes. Nesse contexto, crescem os mecanismos de controle sobre as mulheres, como teorias elevadas a status supostamente "científicos": por exemplo, como as mulheres não ejaculariam, elas não teriam orgasmo; por conta disso, os homens seriam mais carentes de relações sexuais e prazer do que as mulheres, seriam eles mais "fogosos" do que elas. Estas seriam muito mais afetivas e muito menos sexuadas - "o ato sexual para elas seria carinho; para os homens, luxúria e prazer" (p. 72). E a resignação para as mulheres seria assim explicada: "É possível... conter a carência das mulheres por sexo, bastando uma boa educação e uma saudável disposição de espírito para a mulher manter-se fiel a seu marido, por mais monstruoso que este fosse, por mais insatisfatória a relação entre eles" (p. 72). A síntese de amor e sexualidade, essencial ao amor individual sexuado, de que fala o autor de A origem da família, da propriedade privada e do Estado, uma das consequências do individualismo burguês em seu período progressista, passa a ser fortemente negada pela família burguesa madura. Na era vitoriana, portanto, "uma Julieta não poderia ter lugar algum entre as mulheres respeitáveis" (p. 73).

A situação na classe trabalhadora, ainda que por outras mediações, não era diferente, conforme defende Lessa. De acordo com Marx e Engels, como a dissolução do matrimônio dos trabalhadores era mais fácil, por possuírem como única propriedade a sua força de trabalho, a possibilidade de desenvolvimento do autêntico amor sexuado individual entre eles seria maior. Por outro lado, o fato de as mulheres trabalharem fora, o que não acontecia nas famílias burguesas, não significaria que as tarefas domésticas e de criação dos filhos tivessem deixado de ser serviço privado a ser prestado pelas mulheres - a questão da dupla jornada. 


\section{temporalis}

O primeiro ponto de ruptura entre as necessidades e possibilidades do amor individual sexuado e o casamento monogâmico burguês se dá na Primeira Guerra Mundial (1914-1918). O movimento sufragista das mulheres, o crescimento da social-democracia com forte base operária e a literatura revolucionária por ela impulsionada, a explosão do consumo de romances, peças teatrais etc. confluíam na direção de elevar à consciência, em escala social, a contradição entre as relações sociais vigentes e predominantes e o amor sexuado individual. Até mesmo a hecatombe da Grande Guerra iria contribuir para tal fluxo, haja vista o fato de muitas mulheres terem de assumir o posto de chefe da família por conta das sequelas belicosas (mortes, mutilações etc.).

O movimento revolucionário na Rússia e a organização de um movimento comunista em escala mundial abriam novas possibilidades ao desenvolvimento do amor sexuado individual. Alargava-se o espaço para as individuações femininas, em que muitas se tornavam escritoras, poetisas, jornalistas etc., o que não mais se encaixava no padrão esposa/prostituta, ficando o padrão vitoriano de marido, em parte, obsoleto. Na visão de Lessa, esse avanço veio seguido de um recuo. De acordo com ele, o fortalecimento do casamento monogâmico na URSS de Stálin, do patriarcalismo no interior da III Internacional e da ideologia burguesa pela ação do Estado de Bem-Estar Social nos países capitalistas centrais - e, por consequência, da família monogâmica - favoreceram a perda de muitos desses avanços. É a partir dessa situação - e dos seus desdobramentos - que os movimentos feministas vão se erigir nos anos 1960. A luta agora seria pela igualdade das mulheres na sociedade burguesa, entre homem e mulher no interior do casamento monogâmico e no mercado de trabalho, e não mais contra a família monogâmica.

[...] a luta pela libertação das mulheres não é o estabelecimento da igualdade entre maridos e esposas/ prostitutas, mas sim a superação dos fundamentos sociais que converteram em serviço privado a criação das crianças e as atividades de cuidado da comida, da moradia, etc. ou o intercurso sexual. Pouco importa, aqui, se marido e mulher compartem de 
modo rigorosamente igual as tarefas domésticas e de criação dos filhos (p. 77, grifo nosso).

A inédita reação das mulheres ao patriarcalismo vista nas últimas décadas, via movimento feminista, é marcada pelo predomínio de uma concepção que vai diminuir o peso da contradição entre "o casamento monogâmico e o pleno desenvolvimento das pessoas (masculinas e femininas)" e substituí-la por uma pobre "questão de gênero" entre homens e mulheres. Partindo da constatação de que a opressão das mulheres ocorre em todas as classes sociais e da compreensão de que nos países socialistas o problema não era menos grave, o feminismo adotou a tese de total autonomia da questão feminina em relação às classes sociais.

O conteúdo histórico do que seria a tal "condição feminina" sofre, então, uma brutal redução: não mais seria uma expressão das alienações que brotam da propriedade privada (isto é, da exploração do homem pelo homem), mas expressão do desequilíbrio relativo do local ocupado pelos homens e pelas mulheres na sociedade "contemporânea". Nossa sociedade deixa de ser caracterizada como uma sociedade de classes e passa a ser denominada como uma sociedade "assimétrica". Corrigidos tais desequilíbrios, a questão estaria resolvida (p. 82).

A concorrência e o individualismo, típicos da sociedade burguesa, adquirem um novo reforço, expresso na luta pelas "mulheres" para ocupar o lugar "dos homens". Essa perda de perspectiva histórica é, assim, facilmente absorvida pela sociedade burguesa, que, via governos neoliberais, apresenta como "soluções" as "políticas afirmativas". Além disso, o capital teve a liberdade que precisava para impor as modificações que a sua crise estrutural lhe impunha - a exploração das mulheres no mercado de trabalho aumentaria significativamente. De acordo com Lessa, Mészáros teria analisado e demonstrado os avanços pontuais das "lutas de gênero", que, no entanto, por limitar suas críticas a aspectos pontuais do "sistema do capital", teriam sido absorvidas por este, passando a funcionar como "legitimadoras ideológicas da totalidade do sistema" (p. 90). Os "imperativos" materiais do sistema seriam tão avassaladoramente predominantes que modificações como direito ao voto, leis contra a violência 


\section{temporalis}

doméstica, ou mesmo a maior participação delas nos postos de poder não teriam força para aproximar as mulheres de um estágio emancipado. A incorporação no mercado de trabalho como parte do processo de tentativa de equalizar a "crise estrutural" do capital degradaria as condições de vida das mulheres, além de contribuir decididamente para o desaparecimento da forma vitoriana da família burguesa. Isso, contudo, não quer dizer que os processos de individuação adquiriram outra qualidade. Ao contrário, diz Lessa: "[...] perdida a ancoragem histórica no patriarcalismo típico, as pessoas buscam alternativas da maneira como a sociabilidade burguesa em crise lhes possibilita, isto é, pelo fortalecimento do seu individualismo e pelo processo de coletivo isolamento" (p. 91). Do ponto de vista mais geral, histórico, portanto, os avanços de "gênero" não iriam além do nível da igualdade formal.

É evidente que algumas das teses defendidas por Lessa estão longe de serem consensuais e de não despertarem polêmicas. A própria questão de "avanços" ou "recuos", "ganhos" ou "concessões absorvíveis pelo sistema do capital", das "lutas de gênero", merece ser confrontada, embora não queira dizer que esta seja feita de modo arbitrário. O risco de uma leitura exageradamente unilateral, absoluta e insuficientemente multidimensional do problema deve ser acrescido do fato de que algumas de suas conclusões, mesmo que forte e rigorosamente dirigidas pelo método marxiano, estariam mais próximas de uma opinião, ainda que contida e equilibrada, do que uma decorrência necessária da exposição. É preciso dar espaço à dúvida! - e ao debate. Outro ponto de polêmica diz respeito ao "amor exclusivista", que Engels teria dito ser a essência, numa sociedade emancipada, do amor individual sexuado, agora liberto das alienações da propriedade privada. Baseado no livre consentimento, na livre escolha, liberto da propriedade privada e do patriarcalismo, o amor sexuado atingiria um nível superior de monogamia. Lessa discorda do pensador alemão porque, segundo ele, partindo do princípio de que as obras de arte são um bom reflexo de uma dada época histórica, elas, por seus enredos e tramas, desautorizariam pela história de seus personagens o "exclusivismo" de um autêntico amor. Escreve Lessa: 
Os dramas existenciais, as dores afetivas, os sofrimentos individuais, as concessões que os indivíduos precisam fazer nas situações em que dois grandes amores são vividos ao mesmo tempo são tão frequentes na literatura que seria razoável postularmos que hoje os indivíduos revelam a capacidade de amar mais de uma pessoa ao mesmo tempo (p. 94).

Aqui a questão é o risco de pegar a exceção pela regra - ainda que o autor ressalve ser "as dolorosas escolhas" uma experiência "generalizada". Saber em que medida as pessoas envolvidas na experiência que o autor diz ser "mais generalizada do que reconhecida" se encontrariam ou não sob o dilema típico da era burguesa - escolher ou ser forçado a escolher entre o "casamento arranjado" (pelas questões econômicas aludidas) ou o autêntico e verdadeiro amor - seria uma problematização necessária, para se saber - de fato - a partir de quais circunstâncias os "indivíduos estariam amando mais de uma pessoa ao mesmo tempo". Aliás, em que medida, a partir da reflexão do autor, as "dolorosas escoIhas" teriam sido feitas pela mediação do patriarcalismo? Não seria uma tendência imanente ao autêntico amor a sua inclinação para o "exclusivismo"? Será que os envolvidos na trama, imbuídos aqui de amor verdadeiro, concordariam simultaneamente em dividir o(a) amante com outro(a)? O verdadeiro amor, ainda que a sua duração seja variável entre os indivíduos, teria a mesma força que possui no "exclusivismo" em uma comunidade de mulheres - se comparássemos, analogamente, com o "modelo" de Platão, por exemplo? Outra questão também seria saber se a pessoa envolvida com esses dois grandes amores, ambos ao mesmo tempo, teria a força e a potência afetiva de que fala o autor para transpor os indivíduos a novos e mais elevados patamares de individuação. Diferentemente das relações instantâneas e artificiais, que não teriam capacidade de manter os indivíduos num patamar rico e mais avançado de interações com a sociedade (e consigo próprios), os grandes amores teriam significativa força de permanência na vida dos indivíduos, além de contribuírem para frear, em parte, as alienações.

Nesse sentido, já em relação ao fato de Engels chamar de monogamia a forma mais livre de relação afetiva, Lessa considera 


\section{temporalis}

não ser adequado usar a mesma designação que o próprio autor utiliza para falar da opressão feminina, alegando ser isso "fonte de enormes confusões". Aqui, não podemos culpar o pensador alemão pelo que os marxistas fizeram com o seu legado, pelas suas deturpações. Por fim, quando o autor diz que a História teria refutado Marx e Engels em relação à possibilidade de o autêntico amor florescer no seio da classe operária (por esta não possuir propriedade), talvez tenha faltado a essa reflexão o fato de os meios de comunicação, por exemplo, no século XX terem avançado nos processos de estandardização e anulado em escala crescente - ainda que potencialmente embrutecidas - as possibilidades de desenvolvimento autêntico das personalidades individuais. Apesar dessas considerações, não queremos aqui dizer que os textos engelsianos não encontrem limites por terem em si as marcas de uma época - a dissolução da forma vitoriana de família monogâmica certamente traz elementos novos para a análise.

Por ser uma investigação original, de uma temática pouco discutida entre as gerações mais novas, por ser um estudo rigorosamente ancorado em sólidos pressupostos marxistas, fruto de uma pesquisa séria e profunda, e por ser um dos autores mais dedicados e engajados da tradição marxista brasileira atual, a leitura de Abaixo a família monogâmica! é não somente necessária, como também imprescindível! 